Ryszard Henryk Solik

Uniwersytet Śląski w Katowicach

(iD) https://orcid.org/0000-0002-8278-1132
Er(r)go. Teoria-Literatura-Kultura Er(r)go. Theory-Literature-Culture $\mathrm{Nr} / \mathrm{No} .41(2 / 2020)$ fotografie/obrazy/projekcje photographs/images/projections ISSN 2544-3186 https://doi.org/10.31261/errgo.8026

\title{
Prawda/y (w) fotografii Od obrazu rzeczywistości do rzeczywistości obrazu
}

\section{The Truth(s) in/of Photography: From the Image of Reality to the Reality of Image}

\begin{abstract}
The issue of "authenticity" of photography has been habitually related to its technical specificity and capabilities. In general, it was concerned about the automatism and inquisitiveness (precision) of the act of preservation, incomparable to the dispositions of traditional image media. It was supposed that those capabilities determine the "real depiction" and photography's typical "ability to confirm the authenticity." It was the rule of analogy, and the relation between a photographic image and the depicted reality that established this criterion of authenticity, much as in the discourses of the truth. This assumption has been called into question in this text, inspired by culturalism and pan-interpretationism. It is insofar as we relate not to the world as such, but rather to the way in which the world exists for us in the realm of certain cultural, social and discursive contexts. In consequence, the issues of the truth and the authenticity of photography are specified in and through interpretation, always within the predetermined discursive strategies and cultural justifications of the interpretive communities. The truth and the photography's authenticity are then dependent inevitably on the context, and subject to discursive conditioning. Furthermore, the actors of interpretation act upon the current convictions of the interpretive communities, which those actors share and perceive as their own.
\end{abstract}

Keywords: truth, photography, interpretation, context, cultural interpretive communities

Prawdę mówiąc, [...] przeświadczenie o zupełnie niezależnym świecie uważam za forme samooszustwa ${ }^{1}$. Joseph Margolis, Czym, w gruncie rzeczy, jest dzieło sztuki?

Czym jest prawda (w) fotografii? A może prawdy? Jak myśleć o doświadczeniu prawdy w procesie percepcji zdjęcia? Czy prawdziwe jest to, co widzimy, co jest widzialne? Zaczynamy, pytając, nie tylko ze względu na naturalną - jak to ujął swego czasu Hans-Georg Gadamer - "uprzedniość pytania wobec wszelkiego

1. Joseph Margolis, Czym, w gruncie rzeczy, jest dzieło sztuki? Wykłady z filozofii sztuki, red. Krystyna Wilkoszewska, przeł. Wojciech Chojna i inni (Kraków: Wydawnictwo Universitas, 2004), 55. 
odsłaniającego rzeczy poznania i mówienia"2, ale również dlatego, że "pociąga to za sobą wyraźne ustalenie przesłanek [...], w horyzoncie których ukazuje się"3 przedmiot pytania. Z tym zaś wiąże się myślenie zarówno o przyjętych ramach refleksji, w obszarze których będziemy się poruszać, jak i strategii interpretacyjnej. Oczywistością jest, że zagadnienie to można problematyzować na wiele sposobów. Więcej nawet, jeśli umiejscowić je w szerokim kontekście współczesnej "cywilizacji obrazkowej" i komunikacji wizualnej, to pytanie o prawdę fotografii okazuje się w gruncie rzeczy także (uwzględniając odrębności techniczne i specyfikę medium) pytaniem o prawdę obrazu. A "kto pyta o obraz, pyta o obrazy, o nieprzejrzaną liczbę mnogą"4. Nie będziemy się jednak zajmować tak szerokim i zdywersyfikowanym obszarem. Ograniczmy się do refleksji, na tyle, na ile to możliwe, o i wokół fotografii. Refleksji, dopowiedzmy wyraźnie z pełną świadomością, zawsze cząstkowej, aspektowej, stronniczej, bo formułowanej za każdym razem - to już prawie truizm - z jakiejś perspektywy, umiejscowionej w jakimś kontekście dyskursu i interpretacyjnych przesłanek. Od tego nie ma ucieczki, podobnie - co wiemy choćby od Friedricha Nietzschego - nie ma nieinterpretowanych samoistnych wobec teorii faktów ${ }^{5}$. Stąd też "[...] nie istnieje coś takiego jak 'najlepsze wyjaśnienie' czegokolwiek”, w zamian mamy do czynienia z wyjaśnieniami, co najwyżej, "najlepiej odpowiadającymi celom tego, kto wyjaśnia". Z jaką więc perspektywą oglądu mamy tutaj do czynienia? W niniejszym tekście zakorzenionym w kulturalizmie i paninterpretacjonizmie, najogólniej rzecz ujmując, zagadnienie prawdy i prawdziwości fotografii łączymy z doświadczeniem interpretacji kontekstualnie determinowanej. Uznając współzależność percepcji i interpretacji (jako własności ontologicznej), nieuchronnie zależnej od kontekstów, racji i przesądzeń kulturowych, krytycznemu przemyśleniu poddajemy szereg ugruntowanych potocznym doświadczeniem kwestii, rzekomo decydujących o prawdzie i prawdziwości fotografii. Wychodząc od relacji fotografii wobec rzeczywistości, a ściślej kulturowych (i tym samym interpretacyjnych) konstruktów rzeczywistości, następnie dylematów klasycznej (korespondencyjnej) teorii prawdy, podążamy ku fotografii “legitymizującej” rzeczywistość oraz prawdzie fotografii

2. Hans-Georg Gadamer, Prawda i metoda. Zarys hermeneutyki filozoficznej, przeł. Bogdan Baran (Kraków: Wydawnictwo Inter esse, 1993), 338.

3. Gadamer, Prawda..., 338.

4. Gottfried Boehm, O obrazach i widzeniu. antologia tekstów, red. Daria Kołacka, przeł. Małgorzata Łukasiewicz, Anna Pieczyńska-Sulik (Kraków: Wydawnictwo Universitas, 2014), 275.

5. "Z czego powstał tekst świata, a ściślej tekst kultury? Bynajmniej nie z faktów, lecz interpretacji owych faktów, albowiem fakty same nie istnieją. Istnieją tylko ich interpretacje”. Michał Paweł Markowski, Nietzsche. Filozofia interpretacji (Kraków: Wydawnictwo Universitas, 1997), 279.

6. Richard Rorty, Obiektywność, relatywizm i prawda, przeł. Janusz Margański (Warszawa: Wydawnictwo Aletheia, 1999), 91. 
konstytuującej się w interpretacji i poprzez interpretacje. Zawsze w kontekście racji doraźnych systemów dyskursywnych i wspólnot interpretacyjnych, z pułapu których prawda okazuje się konstruowana i wyznaczana.

W świetle tak zarysowanej organizacji wywodu skoncentrujmy się zatem najpierw nad tym, jak pojmowano i definiowano prawdę i "prawdziwość" fotografii, jej wiarygodność i dokumentalną wartość źródła. Nie chodzi jednak w głównej mierze o sferę określonych, takich czy innych kryteriów, ile o to, co kryteria te sytuacyjnie uprawomocniało, a tym samym wyznaczało potencjalne (kontekstualne) konsensy prawdy. Wszak nasze myślenie o czymś, rozumienie i definiowanie czegokolwiek to pochodne doraźnych rekonstrukcji semantycznych. Zawsze zależnych od strategii dyskursywno-interpretacyjnych, które same nie są nigdy wolne od wpływów historii i kultury oraz "horyzontu naszych uprzedzeń, który nigdy nie pozostaje taki sam ani też nie osiąga momentu ostatecznego zamknięcia”" . Dotyczy to zarówno interpretacyjnych projekcji-obrazów świata, jak i narzędzi i teorii, za pomocą których obrazy te konstruujemy. Dawno bowiem zakwestionowano neutralność języka opisu, a raczej narracji, podobnie zresztą ideę czystego doświadczenia ${ }^{8}$. Residuum prawdy czynimy więc doświadczenie interpretacji, jako de facto rozstrzygające nie tyle o prawdzie zdeponowanej "w" lub "po" stronie fotografii (stąd w tytule i otwierającym tekst pytaniu "w" wzięto w nawias), ile konkretyzowanej kontekstualnie w procesach percepcji i kreacji zarazem, wyłącznie "za pomocą odpowiednich abstrakcji tworzonych w ramach zmiennych kontekstów".

W konsekwencji przyjmijmy (kulturoznawcy i sympatycy kulturalizmu nie będą mieli z tym problemów), że określoność czegokolwiek jest nieodmiennie określonością kulturowo i kontekstualnie determinowaną ${ }^{10}$. W efekcie uzasadnione wydaje się przypuszczenie, dla niektórych może dyskusyjne, że o prawdzie, także w fotografii, należy myśleć jako o czymś, co w określonych okolicznościach

7. Wojciech Kalaga, Mgławice dyskursu. Podmiot, tekst, interpretacja (Kraków: Wydawnictwo Universitas, 2001), 39.

8. Zob. Thomas Kuhn, Struktura rewolucji naukowych, przeł. Helena Ostromęcka (Warszawa: Wydawnictwo PWN, 1968).

9. Margolis, Czym, w gruncie rzeczy..., 126.

10. Podzielam tutaj całkowicie stanowisko, między innymi Andrzeja Szahaja, Stanleya Fisha, Jerzego Kmity i wielu innych, "podtrzymujące prymat kultury pojmowanej jako zespół przekonań powszechnie respektowanych w danym społeczeństwie (ewentualnie węziej - grupie społecznej) wobec ontologicznego 'umeblowania świata' oraz sposobu jego poznawczego konstytuowania; prymat zatem wobec wszystkiego, co jawi się jako istniejące oraz istniejące w sposób taki to a taki". Innymi słowy to właśnie "kultura stanowi warunek istnienia każdego bytu jako bytu jakoś określonego”. Andrzej Szahaj, “Zniewalająca moc kultury” [Przedmowa], w: Stanley Fish, Interpretacja, retoryka, polityka. Eseje wybrane, red. Andrzej Szahaj, przeł. Krzysztof Abriszewski i inni (Kraków: Wydawnictwo Universitas, 2008), 15. 
i dyskursach za takową byliśmy lub będziemy skłonni uznać i uważać. Rzecz jasna, zawsze $w$ horyzoncie aktualnie podzielanych racji i założeń interpretacyjnych, w gruncie rzeczy ustalających zakorzeniony w sytuacji koncept prawdy. Nie ma zatem tutaj miejsca na intersubiektywność, ta została "ograniczona, zrelatywi-

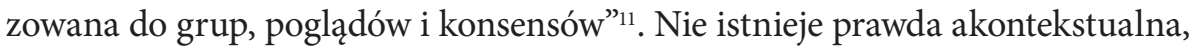
niesytuacyjna, niezinterpretowana, nieumiejscowiona w jakimś doraźnym "uniwersum dyskursu", tak jak nie ma mowy o bezstronności narzędzi werbalizacji czy bezzałożeniowym rozumieniu czegokolwiek. W tym ujęciu o wyraźnie antyfundacjonalistycznej proweniencji - identycznie jak w perspektywie ponowoczesności - myślimy o prawdzie, która nie jest dana i odkrywana, lecz spolecznie i dyskursywnie wytwarzana (konstruowana) ${ }^{12}$. A wpisana w te procesy "[...] historyczność myśli jest nie tyle istotną cechą myśli" jako takiej, "lecz, z braku lepszej alternatywy, pójściem o zakład, że esencjalizm i modalna inwariantność są [także w domenie prawdy] skazane na porażkę"13. Obecność pojęcia jest więc zawsze obecnością sensu temporalnie stanowionego, konkretyzacją kształtowaną w kontekście historii i kulturowo uwarunkowanej infrastruktury poznawczej ${ }^{14}$. Z tej też perspektywy, bodaj najbardziej kontrowersyjny fragment powyższego założenia, stwierdzenie - byliśmy lub będziemy skłonni uznać i uważać - wymaga niezbędnego dopowiedzenia. Nie chodzi, podkreślmy to z całą mocą, o indywidualne upodobania, a co za tym idzie - jednostkowe kwalifikacje (zwykle skazane na potencjalne relatywizacje), ile raczej o to, co pozornie indywidualne w końcu okazuje się społeczne i kulturowe. O kwalifikacje zależne od respektowanych strategii dyskursywnych, ustanawiane nie tyle mocą indywidualnej świadomości, ile pod wpływem presji “wspólnot interpretacyjnych” (Stanley Fish) oraz kulturowej infrastruktury rozumienia. Bo też “indywidualny umysł - pisze Wojciech Kalaga - nie ma w tym względzie żadnej mocy ontologicznej (tj. mocy ustanawiania społecznie rozpoznawalnych przedmiotów czy jakości). Ta moc

11. Mieke Bal, Wędrujące pojęcia w naukach humanistycznych. Krótki przewodnik, przeł. Maria Bucholc (Warszawa: Wydawnictwo Narodowe Centrum Kultury, 2012), 35.

12. Zob. Grzegorz Dziamski, Kulturoznawstwo, czyli wprowadzenie do kultury ponowoczesnej (Gdańsk: Wydawnictwo Naukowe Katedra, 2016) - zwłaszcza esej: "Prawda w kulturze ponowoczesnej".

13. Margolis, Czym, w gruncie rzeczy..., 37.

14. Zagadnienie kulturowo determinowanych sposobów postrzegania i poznania oraz związanej z tym odmienności nawyków inferencyjnych przedstawiają między innymi: Wojciech Kalaga, Mgławice dyskursu. Podmiot, tekst, interpretacja (Kraków: Wydawnictwo Universitas, 2001); Michel Foucault, Archeologia wiedzy, przeł. Andrzej Siemek (Warszawa: Wydawnictwo PIW, 1977); Michel Foucault, Historia szaleństwa w dobie klasycyzmu, przeł. Helena Kęszycka (Warszawa: Wydawnictwo PIW, 1987); Michel Foucault. Historia seksualności, przeł. Bogdan Banasiak, Tadeusz Komendant, Krzysztof Matuszewski (Warszawa: Wydawnictwo Czytelnik, 2000). 
ontologiczna zakorzeniona jest w trans-indywidualnej strukturze poznania”"15. Mowa tedy o doraźnych konkretyzacjach, będących rezultatem sytuacyjnych uwikłań i dyskursywnych negocjacji, "[...] konstruowanych i nieustannie rekonstruowanych w procesie historii"16. Zważywszy jednak, że problem prawdy $\mathrm{w}$ fotografii można rekontekstualizować na wiele sposobów, uwzględniających - co naturalne w humanistyce - różne punkty widzenia i interpretacyjne strategie, zwróćmy się w pierwszej kolejności ku temu, co czynimy punktem wyjścia, co najbardziej oczywiste i ugruntowane potocznym doświadczeniem. A ścisłej rzecz ujmując, ku temu, co podległo skonwencjonalizowaniu i takim nam się wydaje w perspektywie uznanych praktyk kulturowych i dyskursywnych.

Myśląc o prawdzie fotografii, eksponowano zwykle (do dziś zresztą aktualne, choć w kulturze symulakrów bardziej złożone i problematyczne) kryterium relacji zdjęcia wobec utrwalanej, pokazywanej rzeczywistości, ufundowane zasadniczo na "przymusie analogii". Miała się ona spełniać i uwiarygodniać w głównej mierze w założeniu "prawdziwego odwzorowania", które siłą rzeczy zyskiwało różne konkretyzacje w obrębie technologicznych ograniczeń przeszłości i możliwości współczesności, ale to technika zasadniczo je warunkowała. Nie możemy przecież zapominać o rozziewie między procesualnymi rytuałami dawnej fotografii a rejestrującymi i multiplikacyjnymi zdolnościami obecnej. Jeśli mamy zatem przez "prawdziwość odwzorowania" rozumieć spontaniczną, momentalną rejestrację świata zewnętrznego o dokumentalnej charakterystyce, to trzeba przyznać, że kryterium to (przynajmniej w sensie technicznym) spełniła przede wszystkim fotografia nowoczesna ze średnio- i wysokoczułymi błonami zwojowymi, a już zwłaszcza technologia cyfrowa. Pozwalająca w mgnieniu oka zarejestrować wszystko, co wyda nam się interesujące i warte utrwalenia. W efekcie przypisywaną fotografii "prawdziwość odwzorowania" zwyczajowo wiązano z jej rejestrującym automatyzmem, zapewniającym stopień odwzorowania rzeczywistości nieporównywalny z mimetyzmem innych przekazów ikonicznych.

Na miejsce zwyczajnej mimesis - powiada Hans Belting - zażądano technicznej gwarancji podobieństwa. Zwątpienie w niezawodność obrazów, opartą na wierze w ich mimetyczne zdolności, stanowiło antropologiczny impuls do wynalezienia technik obrazowych, które nie mogą się mylić, ponieważ cechuje je automatyzm ${ }^{17}$.

Fotografia warunek ten spełnia. Pozostaje nam jeszcze skomentować zasadę analogii. Rzecz jasna, łączono ją zwykle z rejestrującym, zwierciadlanym odtwo-

15. Kalaga, Mgławice dyskursu..., 89.

16. Margolis, Czym, w gruncie rzeczy..., 26.

17. Hans Belting, Antropologia obrazu. Szkice do nauki o obrazie, przeł. Mariusz Bryl (Kraków: Wydawnictwo Universitas, 2007), 55. 
rzeniem fotografowanej rzeczywistości. Innymi słowy, powołując się na techniczną stronę fotografii, zdjęcie ma odwzorowywać rzeczywistość na podobieństwo tego, identyczność nie wchodzi grę, jak widzi oko. Zgodnie z utrwalonymi mniemaniami im wierniej, dokładniej, wnikliwiej, tym lepiej. Z zagadnieniem tym koresponduje również swego czasu dyskutowany na polu semiologii (Peirce, Morris, Eco) problem stopnia ikoniczności przekazów wizualnych. W gruncie rzeczy innym językiem opisujący skalę podobieństwa, a co za tym idzie wiarygodności wizualnej znaku (przekazu, zdjęcia) wobec tego, co denotuje ${ }^{18}$. Tak przedstawiony sposób myślenia ma swoje racje, nie można mu też odmówić pewnej spójności, ma też jednak słabości i miejscami razi uproszczeniami. Zapewne automatyzm fotografii i właściwa jej zdolność do rejestracji nieporównywalna z dyspozycjami tradycyjnych mediów obrazowych nie pozostają obojętne wobec przekonania o dokładności i nieomylności zdjęcia (fotografii). Richard Avedon pisał wprost: "nie ma czegoś takiego jak niedokładność w fotografii. Wszystkie fotografie są dokładne", ale też dopowiadał "żadna z nich nie jest prawdą". Problem zatem w tym, że przedstawione argumenty zdają się satysfakcjonujące tylko na pewnym poziomie uogólnienia. Szczególnie wrażliwym polemicznie punktem wydaje się "prawdziwość odwzorowania", łączona przede wszystkim z technicznymi możliwościami fotografii. Do tego dochodzi jeszcze fundamentalna dla niej, a ściślej znów uzależniona od technicznej specyfiki medium, nieuchronność transkrypcji realnego (trójwymiarowej rzeczywistości) na dwuwymiarową płaszczyznę obrazu. Mamy tedy do czynienia z reprezentacjami rzeczywistego, a jak powiada Mieke Bal, “jak wszystkie reprezentacje, nie są one same w sobie ani proste, ani adekwatne”19. Ponadto rejestrujące zdolności narzędzia nie determinują wyłącznie odwzorowującej, dokumentalnej charakterystyki zdjęcia. Podobnie pozornie rejestrująca fotografia niejednokrotnie nie tyle odtwarza czy dokumentuje, ile kreuje rzeczywistość, w pogoni za potencjalnym i nieobecnym. Przymus analogii wyrażający się w precyzyjnym naśladowaniu tego, jak świat nam się jawi i przedstawia (bo przecież nie jakim jest naprawdę), nie oznacza wyłącznie odwzorowania czy wierności wobec rzeczywistości. Media społecznościowe, w szczególności narracje Instagrama (choć nie tylko) są tego znamiennym wyrazem. Jak pisze Mariola Sułkowska: "aparat fotograficzny, skazany na kopiowanie zewnętrznego świata, nie jest poręcznym narzędziem łatwej idealizacji”" ${ }^{20}$. Niemniej pozwala na wiele i wiele możliwości stwarza, a w powiązaniu z oprogramowaniem do edycji zdjęć

18. Szerzej o tym: Umberto Eco, Nieobecna struktura, przeł. Adam Weinsberg, Paweł Bravo (Warszawa: Wydawnictwo KR, 1996) zwłaszcza część “Spojrzenie nieciągłe”, punkt II. Znak ikoniczny.

19. Bal, Wędrujace pojęcia..., 47.

20. Mariola Sułkowska, "Ciało w fotografii”, Kultura Wspótczesna nr 1-2 (23-24)/2000, 106: https://www.nck.pl/upload/archiwum_kw_files/artykuly/15._mariola_sulkowska_-_cialo_w_fotografii.pdf (6.11.2019). 
podlegają one wydatnemu zwielokrotnieniu, włącznie z pokusą konfabulowania i zaklinania rzeczywistości.

Czym zatem jest prawda (w) fotografii? Wiarygodnością obrazu o mimetycznej charakterystyce, śladem realnego? Wiarygodnością wizualnego i widzialnego? Notacją codzienności? Pochodną medium, zdolnego (do niedawna jeszcze) jak żadne inne do rzeczowej zobiektywizowanej rejestracji rzeczywistości? Konsekwencją technologicznie warunkowanej "prawdziwości” zdjęcia ujawniającego jak się rzeczy mają, zdolnego do uchwycenia świata takim, jakim jest? Ten sposób myślenia o fotografii i jej relacji do przedstawionego lub raczej pokazywanego wyrasta $\mathrm{z}$ ugruntowanego mniemania o utrwalającej i odzwierciedlającej naturze fotograficznego medium. Zdaje się własnością fotografii jako takiej, a wręcz konstytutywną (choć nie zapominajmy też o własnościach intencjonalnych i perswazyjnych) fotografii reportażowej, prasowej, ulicznej, reklamowej, modowej, produktowej czy dokumentalnej. Jak pisze Susan Sontag, "malarz konstruuje, fotografik odsłania" ${ }^{2}$. Roland Barthes zaś dodaje, iż "fotografia nie może wykraczać poza język deixis, czystego pokazywania”, a właściwa jej "zdolność poświadczania autentyczności bierze w fotografii górę nad zdolnością przedstawiania”22. Zdrowy rozsądek ${ }^{23}$ i prawdopodobieństwo tego, że także dziś większość posiadających oraz użytkujących aparaty cyfrowe czy smartfony (co nie znaczy fotografów) zwyczajnie podzieli to przeświadczenie, uwiarygodniają domniemanie, że chodzi właśnie o ów rejestrujący profil fotografii, migawkowy i spontaniczny zapis, utrwalający, jak się wydaje, wszystko, co uczynimy przedmiotem fotograficznego kadru. Z czego zresztą tak wielu chętnie dziś korzysta. Nie znaczy to jednak, że formułę tę, pozycjonującą specyfikę fotografii poprzez tak pojmowaną relację do przedstawionego, należy uznać za rozstrzygającą, a tym bardziej wyczerpującą nasze myślenie o naturze tego medium. To byłoby dalekim uproszczeniem. Zwłaszcza w kontekście współczesnego dyskursu o fotografii i kryzysie reprezentacji. Trzeba w tym raczej dostrzec rodzaj utrwalonego uogólnienia. Wprawdzie relacyjność i zakorzenienie fotografii/zdjęcia wobec rzeczywistości zazwyczaj nie podlegają dyskusji (choć nie zapominajmy o Baudrillardzie i wielu innych wieszczących autonomiczność znaku "odzyskującego pełnię praw po śmierci wszelkiej referencji”"24), zyskują

21. Susan Sontag, O fotografii, przeł. Sławomir Magala (Warszawa: Wydawnictwo Artystyczne i Filmowe, 1986), 86.

22. Roland Barthes, Światło obrazu. Uwagi o fotografii, przeł. Jacek Trznadel (Warszawa: Wydawnictwo Aletheia, 1996), 10.

23. Odwołując się do tego pojęcia, myślimy nie tyle o wsłuchiwaniu się to, co "wieść gminna niesie”, w jakieś oddolnie kształtowane opinie czy przesądy, ale ugruntowane, ogólnie przyjęte i funkcjonujące w szerokim obiegu społecznym przeświadczenia.

24. Jean Baudrillard, "Precesja symulakrów", przeł. Tadeusz Komendant, w: Postmodernizm. Antologia przekładów, red. Ryszard Nycz (Kraków: Wydawnictwo Baran i Suszczyński, 1998), 181. 
jednak różne konkretyzacje. Jak to często bywa, problem okazuje się bardziej złożony i skomplikowany niż się wydaje. Co więcej, wrócimy do tego w dalszej części tekstu, kryterialna efektywność tej formuły okazuje się zwodnicza w sytuacji wykroczenia poza obszar powszechnego mniemania i zdrowego rozsądku. Mowa tutaj o uogólnieniu nie tyle w kontekście podzielanych zwykle mniemań, ile w głównej mierze ze względu na to, że stwierdzeniem tym odwołujemy się przede wszystkim do technicznej specyfiki generowania zdjęcia oraz sprzężonej z tym struktury wizualnej. Pomijamy przy tym wiele zmiennych określających sam proces fotografowania i jego społeczne czy kulturowe konteksty (w relacji zarówno do fotografującego, jak i potencjalnego odbiorcy), a także, mające istotne znaczenie, sposoby prezentacji. A przecież fotografie, jak obrazy, mają "w nieubłagalny i niekwestionowany sposób charakter społeczny, usytuowane w konkretnych, historycznie tworzonych światach" 25 . W każdym razie utarło się przekonanie, że "prawdziwość" zdjęcia określa zasada analogii wobec realnego i warunkujący ją techniczny automatyzm rejestracji, czyniące $z$ fotografii odbicie i świadectwo rzeczywistości. "Obraz fotograficzny - podkreśla raz jeszcze Belting - nie jest czymś wynalezionym [Erfindung], ale czymś znalezionym [Fundsache], czymś, co powiela [...] tak prawdziwie, jak to zagwarantować może tylko technika. A jeśli technika nie może się mylić, to jej rezultat także nie jest pomyłką"26. $\mathrm{Z}$ tym wiązano dokumentalny, rejestrujący walor fotografii oraz faktograficzną wartość źródła. To zasadniczo odróżniało ją od innych mediów mimetycznych, w szczególności sztuk plastycznych. W aspekcie zobiektywizowanej notacji imitatywnie i mimetycznie zorientowane malarstwo nie miało szans z realnością fotografii. W istocie, gdy przychodzi nam zestawiać zdjęcia z zagłady, fotografie z obozów koncentracyjnych czy sowieckich łagrów, zdjęcia egzekucji i deportacji ze sztuką na różne sposoby mierzącą się z traumą wojny, dosłowność dokumentu fotograficznego zdaje się porażająca. To dosłowność świadectwa. W tej konfrontacji fotografia okazuje się wiarygodniejsza jako "medium spojrzenia" i rejestracji. Najbardziej nawet uznane dzieła sztuki traktujące o wojnie nie mają właściwej fotografii dokumentarnej bezpośredniości. Przedstawienia okrucieństw i bestialstwa najemnych wojsk w rycinach Jacques’a Callota czy Francisco Goyi, choć na swój sposób zdekonstruowały skonwencjonalizowany przez malarstwo batalistyczne czy "wojennych artystów" obraz wojny, mają się nijak do faktograficznej dosłowności, czy to fotografii Rogera Fentona z wojny krymskiej, czy późniejszych zdjęć wojny secesyjnej. Nie wspominając już o fotografii współczesnej.

25. Fred Myers, Painting Culture: The Making of Aboriginal Hight Art (Durham: NC Duke University Press, 2001), 257, cyt. za: Gillian Rose, Krytyczna metodologia badań nad wizualnością, przeł. Ewa Klekot (Warszawa: Wydawnictwo PWN, 2015), 257.

26. Belting, Antropologia obrazu..., 222. 
Obiektywizm fotografii - pisze André Bazin - nadaje obrazowi siłę wiarygodności nieistniejącą w innych utworach plastycznych. Nasz zmysł krytyczny może nam podsunąć różne zastrzeżenia, lecz musimy wierzyć w istnienie przedstawionego na fotografii, to znaczy obecnego rzeczywiście w czasie i w przestrzeni. Fotografia korzysta z tego, że realność przedmiotu przenosi się na jego reprodukcję ${ }^{27}$.

Jakby tego było mało, musimy jeszcze pamiętać, uwzględniając różnice widzenia oka i obiektywu (o czym wcześniej wspomniano), że reprodukcja-zdjęcie dosłowniej i wnikliwiej rejestruje kadrowaną rzeczywistość. Oko ludzkie i mózg koncentrują się na tym, na co patrzymy, unieważniając detale otoczenia, choćby nawet były detalami tego samego planu. Tymczasem fotografia z jednolitą wrażliwością i pietyzmem (co może mieć swoje zalety, ale też wady) odtwarza i utrwala wszystko, co uchwyci kąt obiektywu i gębia ostrości. Pozwala tym samym zobaczyć to, czego zwykle nie widzimy, a ściślej - nie zauważamy na co dzień.

Podsumujmy dotychczasowe uwagi. Przedstawiony sposób myślenia o prawdzie/ prawdziwości fotografii, najogólniej rzecz ujmując, konstytuuje się w odniesieniu do świata zewnętrznego, uwiarygodniające umocowanie zyskując w (ko)relacji, a ściślej, zgodności fotografii z rzeczywistością. Zależność ta wyznacza swoiste condito sine qua non dotychczasowego wywodu. Niezależnie jednak od tego, jak będziemy konkretyzować odniesienie do rzeczywistości czy też dyskutować o niej samej, niezbędność korelacji skłania na rzecz porzucenia - co z pewnością ucieszy kulturoznawców i zwolenników Cultural Studies - esencjalistycznego pojmowania prawdy, lokując ją zdecydowanie w domenie własności relacyjnych i konwencjonalnych. Tą kwestią przyjdzie nam się jeszcze zająć pod koniec tekstu, bo pozostaje w ścisłym związku z założoną strategią oglądu. Wracając natomiast do wymogu zgodności, musimy pamiętać, że można o niej mówić zarówno ze względu na utrwalone mniemania i potoczność doświadczenia (fotografujących) przenoszącego "realność przedmiotu na jego reprodukcję", co oznacza, że istnienia tej realności nie sposób kwestionować, jak i w perspektywie atrybutywnych własności fotografii: "obiektywizmu” (Bazin) łączonego z "techniczną gwarancją podobieństwa” (Belting), a także właściwej jej "zdolności poświadczania autentyczności" (Barthes).

Przedstawiona narracja uprawomocnienie zyskuje jednak nie tylko w aspekcie technicznej specyfiki medium czy racji zdrowego rozsądku, lecz również, czego nie można pominąć, w styczności do dyskursu prawdy, zwłaszcza teorii kla-

27. André Bazin, "Ontologia obrazu fotograficznego", przeł. Bolesław Michałek, w: Fotospołeczeństwo. Antologia tekstów z socjologii wizualnej, red. Małgorzata Bogunia-Borowska i Piotr Sztompka (Kraków: Wydawnictwo Znak, 2012), 424-425. 
sycznej i korespondencyjnej ${ }^{28}$. Wiążąca idea odniesienia, zakładająca zgodność z rzeczywistością, uległa tutaj zdublowaniu. Fotografia zresztą - z oczywistych powodów - okazała się w tym względzie medium niezwykle przekonującym. Zważywszy na złożoność problematyki prawdy i potrzeby niniejszego tekstu, ograniczmy się do kwestii niezbędnych. Teoria klasyczna, chociaż podlegała w "długim trwaniu" rozmaitym ujęciom i reinterpretacjom ${ }^{29}$, kryterium prawdy łączyła nieodmiennie z relacją do rzeczywistości (stanu faktycznego). Co więcej, nawet w przypadku gdy relacyjność nie była wyraźnie eksponowana, stanowiła domniemywany, niekwestionowany niezmiennik kryterialny. Relację tę zresztą różnie konkretyzowano, sięgając do kategorii "zgodności", "identyczności", "odpowiedniości", "korelacji”, "desygnowania faktu” czy "korespondencji”, które także zyskiwały odmienne charakterystyki i uściślenia znaczeniowe. Podobnie korespondencyjna teoria prawdy akcentowała niezbędną styczność z realnym, różnicując pojmowanie samej korespondencji na tak zwane mocne i słabe wersje (reprezentacje). W każdym razie, abstrahując od poszczególnych rozstrzygnięć, wspólnym fundamentem dyskursu prawdy oraz prawdy i prawdziwości fotografii uczyniono przeświadczenie uznające prawdziwe za zgodne z rzeczywistością. Zgodne, lecz nie identyczne. O identyczności nie sposób zresztą myśleć w obszarze struktur znakowych czy transferów semiotycznych, korelacji znaczącego i znaczonego oraz fundamentalnej dla fotografii transpozycji tego, co przestrzenne na płaszczyznę zdjęcia. W największym skrócie zależność i wymóg zgodności wyrazi1 "wczesny" Ludwig Wittgenstein, pisząc: “Tym, co obraz przedstawia, jest jego sens. Jego prawdziwość lub fałszywość polega na zgodności lub niezgodności jego sensu z rzeczywistością. Aby rozpoznać, czy obraz jest prawdziwy, czy fałszywy, musimy porównać go z rzeczywistością" ${ }^{30}$. Od napisania Traktatu logiczno-filozoficznego minęło sporo czasu, wiele również wydarzało się w polu dyskursów prawdy. Można z tezą Wittgensteina polemizować, szukać słabości i pułapek jej prostomyślności. Niemniej wyrażony profil myślenia nie tylko wpisuje się w szereg doraźnych aktualizacji klasycznej/korespondencyjnej teorii prawdy, ale przede wszystkim dotyczy prawdziwości obrazu, co znakomicie koresponduje z ugruntowanymi mniemaniami o utrwalającej i rejestrującej rzeczywistość fotografii.

28. Zapis sugeruje odrębność tych teorii, opinia ta obecnie wydaje się przeważać, lecz niejednokrotnie nazwy te funkcjonowały i funkcjonują wymiennie.

29. Szerzej o tym między innymi: Jan Woleński, Metamatematyka a epistemologia (Warszawa: Wydawnictwo PWN, 1993).

30. Ludwig Wittgenstein, Tractatus logico-philosophicus, przeł. Bogusław Wolniewicz (Warszawa: Wydawnictwo PWN, 1970), 2.221-2.223, cyt. za: Jakub Pruś, “Teorie prawdy: klasyczna, korespondencyjna i semantyczna - próba uściślenia relacji”, Rocznik Filozoficzny Ignatianum XXIV / 2 (2018), 61: https://czasopisma.ignatianum.edu.pl/index.php/rfi (7.12.2019). 
Dotąd mówiliśmy o styczności fotografii z rzeczywistością, wskazując zarazem warunki tej styczności w obrębie nie tylko technicznej specyfiki interesującego nas medium. Teraz przychodzi zwrócić się ku rzeczywistości. Problem w tym, że nie możemy, jak chciał Wittgenstein (i potoczne mniemania), porównać obrazu/ fotografii do rzeczywistości. I nie dotyczy to tylko fotograficznych konfabulacji z Internetu, niejednokrotnie niewiele mających wspólnego z realnością. W efekcie postulat austriackiego filozofa, ale także wszystkich odwołujących się do realnej, pozaobrazowej rzeczywistości, uchodzi za deskryptywnie satysfakcjonujący tylko w domenie zdrowego rozsądku. Wykraczając poza zdroworozsądkowe mniemania, jasno bowiem trzeba stwierdzić, że polem odniesienia czynimy nie tyle rzeczywistość jako taką, ile nasze postrzeganie rzeczywistości. Zawsze kontekstualne, kulturowe, przy tym nieuchronnie determinowane (w sporym uogólnieniu) przez dyspozycje oraz poznawcze własności jednostki oraz wiele rozmaitych sytuacyjnych zmiennych, o czym w dalszej części tekstu. Nie jest możliwe nieuprzedzone, nieusposobione postrzeganie, bo też "niewinne, nieskażone jakąkolwiek formą wiedzy kształtującej percepcję oko widza nie istnieje”31. Nie możemy więc zawiesić niczego w zakresie naszych społecznych (kulturowych) kompetencji czy osobniczych uprzedzeń, jak i interweniującej presji wiedzy już nabytej; niczego, co owe postrzeganie strukturyzuje, co je określa, buduje, kształtuje. Nie możemy wreszcie zawiesić, a to kwestia dla nas fundamentalna, interpretacyjnej aktywności, nie możemy też wnieść się ponad poziom interpretacji, by nie interpretować. Jako że interpretacja okazuje się własnością ontologiczną, nieodłączną od egzystencji, przeobraziła się z "czynności przygodnej” w zasadę obecności, podstawową i - jak pisał autor Prawdy i metody - "pierwotną formę spełnienia się jestestwa będącego byciem-w-świecie" ${ }^{32}$.

Tym stwierdzeniem osiągnęliśmy punkt zamykający (rzecz jasna wyłącznie w zakresie potrzeb tego tekstu) część wynikającą z wyrażonego na początku zobowiązania do przemyślenia tego, co uchodziło za najbardziej oczywiste i ugruntowane potocznym doświadczeniem. A ściślej rzecz ujmując, co w przestrzeni pewnych skonwencjonalizowanych praktyk kulturowych takim się wydaje. Dotychczasowe ustalenia wyzwalają jednak potrzebę przemyślenia problemu w innej jeszcze perspektywie, co nie znaczy nowej. Trzeba w niej bowiem dostrzec jedynie pewną rysującą się możliwość związaną z tym, że rzeczywistość nie tylko nie legitymizuje prawdy i prawdziwości fotografii, bo jako taka jest dla nas niedostępna, ale sama okazuje się - zwłaszcza we współczesnej bądź co bądź silnie

31. Maria Korusiewicz, "Jak funkcjonuje dzieło sztuki, czyli muzeum według Nelsona Goodmana”, w: Muzeum sztuki. Antologia, red. Maria Popczyk (Kraków: Wydawnictwo Universitas, 2005), 137.

32. Gadamer, Prawda i metoda..., 251. 
wizualnej kulturze - przez fotografię i obrazy legitymizowana i konstruowana. Świadomość, że "przedstawienia są naszą formą dostępu do wszystkiego, co istnieje, a nawet - jeszcze dobitniej - są (jak ujął to filozof Nelson Goodman) naszymi 'sposobami tworzenia świata', nie tylko jego odzwierciedlania"33, skłania do przeprofilowania problemu. Co za tym idzie, przejdźmy od korelacji z rzeczywistością do rzeczywistości medialnie kreowanej oraz prawdy wizualnie certyfikowanej. Zważywszy, że nie mogliśmy i nie możemy przekroczyć ograniczeń "światoobrazu”, wyjść poza obrazy-rzeczywistości i jej kulturowe konstrukty (choć niegdyś inaczej to widziano), rysujący się tutaj zwrot nie może być traktowany wyłącznie jako problem teraźniejszości. Niemniej współczesność uczyniła go szczególnie aktualnym w obrębie dylematów reprezentacji i gargantuicznej wprost eskalacji fotograficznych narracji w przestrzeniach mediów społecznościowych.

W tak naszkicowanej perspektywie dylematy prawdy i prawdziwości fotografii odnieśmy jeszcze do zdjęciowych narracji Instagrama i Facebooka. Chodzi o mechanizmy gry obrazem, kształtujące odautorskie narracje, konstruowane w głównej mierze pod kątem prezentowania się innym, ale też samodefiniowania własnej atrakcyjności. Ta gra fotografią/zdjęciami jest tutaj istotna nie tylko ze względu na umocowanie w cyfrowej technosferze współczesności, lecz nade wszystko dlatego, że potwierdza też nośność fotograficznego medium "jako permanentnie niezbędnego miejsca, w którym ciągle zachodzi proces kulturowy, jakim jest kształtowanie i funkcjonowanie podmiotu, konceptualizowanego jako niepewny i niestały" ${ }^{34}$. Innymi słowy narracje te stanowią swego rodzaju próby samookreślenia wystawianej na pokaz tożsamości, a co za tym idzie wytwarzania, ujawnianej i przedstawianej innym, wiedzy o sobie. Rzecz jasna organizowanej z instrumentalną świadomością wyłącznie tego, co autorzy tych zdjęć chcą przekazać i powiedzieć o sobie oraz jak pragną być przez innych postrzegani. Odwołujemy się tutaj do fotograficznych narracji w przestrzeniach internetowych portali również dlatego, że narracje te w makro skali wpisują się w horyzont "obrazowania rzeczywistości", a dokładniej, w ad infinitum konstruowane projekcje rzeczywistości. W "społeczeństwie spektaklu” przedstawienia wizualne, w szczególności fotografia, stały się najbardziej efektownym i jednocześnie efektywnym środkiem snucia portalowych opowieści. To konsekwencja nie tylko technicznych możliwości mediów cyfrowych i nieograniczonej proliferacji obrazów, lecz także stopnia zwizualizowania współczesnej rzeczywistości, w której niemal wszystko, w tym także "nasza polityczna retoryka i prywatne

33. William John Thomas Mitchell, Czego chca obrazy? Pragnienia przedstawień, życie i miłości obrazów, przeł. Łukasz Zaremba (Warszawa: Wydawnictwo NCK, 2013), 28.

34. Griselda Pollock, "Art", w: Feminism and Psychoanalysis: A Critical Dictionary, red. Elizabeth Wright, Blackwell, Oxford 1992, 10. Cyt. za: Gillian Rose, Krytyczna metodologia badań..., 140. 
oczekiwania są określone wizualnie: oczekujemy otwartości i chcemy zajrzeć sobie wzajemnie w głąb duszy" ${ }^{35}$. Najlepszymi tego gwarantami, przynajmniej dla wielu, zdają się więc fotografia i media środowiskowe. Istotnie dysponujemy obecnie środkami, technologiami wytwarzania i pomnażania wizualności, generowania zdjęciowych narracji, nieporównywalnymi z niczym wcześniej. “A wszystkie te różnorodne technologie i przedstawienia wizualne proponują jakieś obrazy świata", bez wątpienia, "żadne z nich [...] nie ukazują tego w sposób niewinny"36 i neutralny. Nigdy wcześniej zresztą konstruowanie tych narracji i wizualne opowiadanie o sobie nie były tak proste i skuteczne zarazem; bo też i media były niegdyś inne, nigdy tak dostępne, powszechne, funkcjonalne. Technologiczne "maszyny widzenia" ${ }^{37}$, jak to określił Paul Virilio, wyzwoliły w zasadzie nieograniczone możliwości kreowania i działania obrazem. Co w aspekcie prawdy obrazu i prawdy wszechobecnej fotografii może być jednak ambiwalentnie rozumiane. $Z$ jednej bowiem strony istotnie ugruntowały znaczenie wizualności i widzenia w dzisiejszej kulturze, z drugiej jednak nadprodukcja wizualności, w tym także fotografii cyfrowej, prowadzi do swoistej inflacji obrazu. Niemniej "widzieć to dzisiaj o wiele więcej niż wierzyć" ${ }^{38}$, powiada Nicholas Mirzoeff. I chociaż nasza kultura w tym uprzywilejowaniu widzialności nie wydaje się odosobniona, komunikaty wizualne, a już zwłaszcza fotografia, uchodzą ciągle za najbardziej wiarygodne i zobiektywizowane przekazy. I zdaje się, że w najbliższym czasie niewiele się w tej kwestii zmieni. Nie zmieniła tego diagnozowana od dawna i postępująca wraz z rozwojem fotografii (o czym pisał już w latach trzydziestych $\mathrm{XX}$ wieku Walter Benjamin ${ }^{39}$ ) autonomizacja świata widzialnego. Nie zmieniły głoszone przez Jeana Baudrillarda oderwanie obrazu od rzeczywistości i szerzące się wizualne symulacje, pozbawione znamion ekwiwalencji. Wydaje się, że nie zmienią tego także ani "wielokrotnie podkreślana inflacja" i nadprodukcja obrazów, mająca swe źródła w ich nadmiarowości i "kompulsywnym wytwarzaniu”"40, ani tym bardziej głosy krytyki kwestionujące prymat wizualności w dzisiejszej

35. Wolgang Welsch, "Na drodze do kultury słyszenia?", przeł. Krystyna Wilkoszewska, w: Przemoc ikoniczna czy "nowa widzialność", red. Eugeniusz Wilk (Katowice: Wydawnictwo Uniwersytetu Śląskiego, 2001), 61.

36. Rose, Krytyczna metodologia badań..., 20.

37. Paul Virilio, "Maszyna widzenia”, przeł. Barbara Kita, w: Widzieć, myśleć, być. Technologie mediów, red. Andrzej Gwóźdź (Kraków: Universitas, 2001).

38. Nicholas Mirzoeff, "What is Visual Culture?", w: The Visual Culture Reader, red. Nicolas Mirzoeff (London-New York: Routledge, 1998). Cyt. za: Rose, Krytyczna metodologia badań..., s. 23.

39. Zob. Walter Benjamin, Anioł historii. Eseje, szkice, fragmenty, przeł. Krystyna Krzemieniowa i inni (Poznań: Wydawnictwo Poznańskie, 1996).

40. Rafał Drozdowski, "Obrazów nigdy dosyć - pod warunkiem, że nie służą jedynie do oglądania”, Kultura Współczesna nr 1(76)/2013. 
kulturze ${ }^{41}$. Większość statystycznych użytkowników Instagrama czy Facebooka z pewnością nie stanowi grupy dotkniętej inflacją fotograficznej nadprodukcji. Działający na internetowych forach i zamieszczający tam regularne fotograficzne aktualizacje to środowiska, bez cienia wątpliwości, odporne na inflację przekazów wizualnych. Za dużo zdjęć, fotografii i "nad-łatwość" ich generowania mimo wszystko nie oznaczają tutaj problemu, raczej symptom możliwości. Nawiasem mówiąc, problemem nie jest sama nadprodukcja obrazów czy skala wizualności, ale - co podpowiada Krzysztof Olechnicki - "kryzys wizualności, objawiający się brakiem znaczenia przypisywanego obrazom" ${ }^{\prime 2}$. W tym miejscu musimy jednak uznać, że dla patrzących na świat przez wizjer aparatu czy ekran smartfona to kwestia nie do przyjęcia. Niejako schizofrenicznej logiki wymagałoby bowiem założenie, że opowiadający o sobie na Instagramie bohaterowie zdjęciowych narracji mogą kwestionować zarazem sens tej aktywności i zamieszczonych tam przekazów. Dla tych, dla których imperatywem podróżowania zdaje się przede wszystkim zaliczenie modnych "destynacji”, pochwalenie się przed bliższymi czy dalszymi znajomymi wpisuje się integralnie w scenariusz zdarzenia. Nie ma zdjęć, nie było wyjazdu. Jakkolwiek brzmi to paradoksalnie, dla wielu nieobfotografowane wojaże, towarzysko nieskonsumowane, to zmarnowany czas i pieniądze; zmarnowana sposobność zaistnienia na internetowych forach, odium straconej szansy i gorycz przemilczenia. Cóż z tego, że byłam/byłem, skoro nikt nie widział, nikt nie wie. Nieujawnione wydarzenie traci rację bytu. Prezentujące się w selfie "ja" to najlepsza forma utrwalenia "udokumentowanej obecności".

Oczywiście trzeba w tym miejscu pytać o prawdę i prawdziwość owych fotograficznych narracji, niejednokrotnie znacząco przypudrowanych, złożonych z selektywnie dobranych przekazów, wyłącznie z tego, co pragniemy opowiedzieć o sobie, czym chcemy pochwalić i podzielić się z innymi. Autor (użytkownik konta) ma tu sporą swobodę operowania materiałem zdjęciowym; decyzyjność o tym, co i jak będzie zamieszczone i prezentowane, leży po jego stronie. Jeśli mieści się w granicach prawa oraz regulacji portalu, niemal w dowolny sposób, włączając w to sferę gustu i wrażliwości, może kreować/konfabulować opowieść o sobie, nie podlegając w zasadzie zewnętrznym opresjom. Co zatem buduje wiarygodność (prawdziwość) tych fotograficznych narracji? Zapewne - dla wielu,

41. “Jeden z największych mitów współczesnych powiada - konstatuje Michał Paweł Markowski - że żyjemy w cywilizacji obrazkowej, że po epoce druku nastała pewna epoka wizualna. To wielkie samooszustwo, które ma służyć lenistwu ducha, któremu nie chce się czytać. [...] Cywilizacja obrazkowa nie oznacza zmiany w percepcji, ale zmianę znacznie gruntowniejszą i przez to dotkliwszą. Otóż cywilizacja nasza nie przeskoczyła od druku do obrazu, ale od druku donikąd". Michał Paweł Markowski, Dzień na Ziemi. Proza podróżna (Poznań: Wydawnictwo Poznańskie, 2014).

42. Krzysztof Olechnicki, “Łap chwilę... powoli”, Kultura Współczesna nr 1/76, 2013. 
jeśli nie większości zainfekowanych "portalozą" - to sam efekt zdjęcia. Dla użytkowników smartfonów i aparatów cyfrowych nie da się go z niczym porównać, niczym zastąpić. Nośność, atrakcyjność, wiarygodność fotografii to konkret unaocznienia i zobiektywizowania. Efekt nie do przecenienia nie tylko dla statystycznych użytkowników mediów społecznościowych, lecz także portalowych graczy, śledzących followerów, a już zwłaszcza sieciowych influencerów. Zresztą to własność konstytutywna dla każdego typu przedstawienia, immanentnie wpisana w charakterystykę ikonicznego przekazu jako takiego. Niemniej fotografia ze swoim rejestracyjnym automatyzmem i "techniczną gwarancją podobieństwa" zdaje się tu medium szczególnie uprzywilejowanym. Idzie też o niezwykłą łatwość sprawozdawczego (niemal reporterskiego) opowiadania o sobie niejako przy okazji, w przelocie. Walor prawdziwości i wiarygodności wydaje się także wzmacniać to, że w naszej wizualnej rzeczywistości dla użytkowników Facebooka i Instagrama nie język a obraz właśnie - trawestując Katarzynę Rosner - stał się, jak się wydaje, "prymarnym narzędziem i medium myślenia, czynnikiem kształtującym percepcję świata i pogląd na świat członków danej społeczności, a dopiero wtórnie środkiem komunikacji”"33.

Konkret unaocznienia to pewna prawda zdjęcia. Jakakolwiek by ona była (będzie zawsze relatywna, kontekstualna, sytuacyjna). Rzecz jasna, tak jak sfera języka nie jest tożsama $\mathrm{z}$ tym, co jest w nim wyrażane, tak fotografia/zdjęcie nie są identyczne z tym, co denotują i przedstawiają. Nie zmienia to jednak faktu, że uwodzi nas, przynajmniej większość i niejednokrotnie jakże skutecznie, narracja wizualnie legitymizowana. Innymi słowy, zazwyczaj okazujemy się bardziej uwrażliwieni na doznania wzrokowe. Mało prawdopodobny wydaje się zarzut nadużycia czy uogólniającej generalizacji wobec stwierdzenia, że wierzymy (nie tylko dziś) bardziej naszym oczom niż uszom. To przypadłość nie tylko obrazkowej kultury. Za wysoce prawdopodobne można uznać przypuszczenie, że dla facebookowych i instagramowych aktorów nawet przekazy wysoce zmanipulowane, przerysowane i konfabulujące realia nie stanowią przeszkody, by za prawdziwe i wiarygodne uznawać to, co widzą i co jako takie jest im przedstawiane. Specjalnie też chyba nie zaprzątają sobie głowy tym, że "prawda widzenia nie jest być może całą prawdą"*4. Rzecz w tym - podpowiada Umberto Eco - "by dostarczyć znak, który jednakże nie ma uchodzić za znak" wcale powiedziane, że znaki te muszą być referencyjne, zakorzenione w realności, że odnoszą do czegoś, co faktycznie zaszło i miało miejsce. Ich denotacyjne racje

43. Katarzyna Rosner, Narracja, tożsamość i czas (Kraków: Wydawnictwo Universitas, 2003), 76.

44. Welsch, Na drodze do kultury styszenia ..., 60.

45. Umberto Eco, Semiologia życia codziennego, przeł. Piotr Salwa, Joanna Ugniewska (Warszawa: Wydawnictwo Czytelnik, 1998), 15. 
konkretyzuje widzialność, stają w prawdzie, która jawi się niejednokrotnie prawdą wyłącznie wizualnie certyfikowaną, co wystarcza, by mieć problem z ewentualnym odgraniczeniem "zjawisk porządku ontologicznego i znakowego". Dylemat ten zdaje się jednak specjalnie nie absorbować uwagi użytkowników internetowych portali. $\mathrm{W}$ większości wszakże owe fotografie znajdują umocowanie w różnych sytuacjach czy wydarzeniach z udziałem nieodmiennie autora prezentowanych zdjęć, o których ten pragnie poinformować. Zwykle przyjmują też formułe "zaświadczenia o swojej obecności", które jawi nam się, jak to celnie i nieco ironicznie skwitował Michał Paweł Markowski, "odwrotnością wyrzynania na drzewie i kamieniu frazy 'Byłem tutaj, Heniu”"'46. Oczywiście sam fakt bytności jest istotny, ale konieczność podzielenia się z innymi tym, gdzie byliśmy i co robiliśmy, zdaje się kwestią nadrzędną. Zresztą narracji tych nie można sprowadzić jedynie do prostej informacji o wydarzeniu, podróży, wakacjach i tym podobnych. To narracje teleologiczne ukierunkowanie, które trzeba uznać za wysoce sfunkcjonalizowane i arbitralne. To wyselekcjonowane zestawy odpowiednio dobranych, a niejednokrotnie wcześniej odpowiednio aranżowanych fotografii. To zdjęciowe opowieści nieraz poddawane różnorakim korektom i retuszom, co najmniej na poziomie edycyjnych możliwości oprogramowania aparatu czy smartfona. A wizualny efekt można znacząco wzmocnić i zintensyfikować, korzystając ze specjalistycznych programów graficznych bądź z rozmaitych szablonów fotonarracji czy fotoksiążek z cyklu "Wakacyjna przygoda". Jeśli i to nie wystarcza, ostatecznie możemy jeszcze oddać się w ręce profesjonalistów, gotowych - jak w przypadku usługi/aplikacji RetouchMe - w każdej chwili i przez dwadzieścia cztery godziny na dobę opracować dla nas idealne selfie, ewentualnie skorygować i poprawić wszelkie niedostatki naszej fizyczności ${ }^{47}$. Ale owe "byłem tutaj” może być również czystą konfabulacją, rodzajem autokreacji, fotomontażem zaświadczającym o wojażach nigdy nie odbytych i niemających miejsca. W wymiarze fotograficznej autokreacji nic nie jest niemożliwe. Realność ustępuje miejsca narracji odpowiednio skonstruowanej. I doprawdy - odwołując się do Stanleya Fisha, można stwierdzić - nie ma znaczenia, iż nie "pozostaje ona

46. Markowski, Dzień na Ziemi..., e-book.

47. "Czy chcesz poprawić swoją twarz i ciało? Nie musisz uczyć się profesjonalnych edytorów zdjęć i edytować zdjęć samodzielnie, aby uzyskać idealne selfie! Zespół projektantów zrobi to na najwyższym poziomie za ciebie. Możemy wyszczuplić, zmienić rozmiar, zmienić kształt i wydłużyć dowolną część ciała. Po prostu wybierz, co chcesz skorygować, a specjaliści z RetouchMe pomogą ci zeszczupleć $\mathrm{w}$ talii, usunąć tłuszcz z brzucha, powiększyć piersi, uzyskać płaski brzuch, usunąć trądzik, pryszcze i zmarszczki, powiększyć usta, zmniejszyć nos, wybielić zęby, wyszczuplić twarz, usunąć cellulit i fałdy tłuszczu, wytworzyć uśmiech, usunąć cień itd.”. Opis ze strony internetowej: https://play.google.com/store/apps/details?id=com.retouchme\&hl=pl (7.12.2019). 
w zgodzie z faktami”, najważniejsze zdaje się to, że z "perspektywy jej założeń fakty są teraz wyznaczane" ${ }^{\text {"48 }}$.

Wiarygodność i prawdziwość fotografii wzmacnia jeszcze jedna kwestia. Przeświadczenie, że widzieć - to wiedzieć. I nie chodzi jedynie o to, że "wiedzieć jest etymologicznie równoznaczne $\mathrm{z}$ widziałem, a większość naszych wyrażeń w zakresie poznawania - wgląd, oczywistość, idea, teoria, refleksja itd. - jest nacechowana wizualnie" ${ }^{\prime 49}$. Chodzi o ugruntowane na dobre powiązanie wiedzy z domeną oka i widzialności; o nieodzowność czynienia widzialnym, a w konsekwencji ujawnienie poprzez udostępnienie wszystkiego, co ważne w perspektywie prowadzonej narracji; innymi słowy wszystkiego, o czym tylko zamieszczający zdjęcia w sieci pragną poinformować. Stąd wszystko jest transkrybowane, rejestrowane i poprzez fotografię czynione widzialnym: począwszy od tego, gdzie byliśmy i jesteśmy, co robimy, różne nasze aktywności, wydarzenia, wojaże, wakacje, podróże, spotkania ze znajomymi, śluby, wszelkie formy konsumpcjonizmu, preferencje kulinarne, na redefiniowanej sferze intymnej skończywszy. Nie ma więc mowy w przestrzeniach Instagrama i Facebooka o "ucieczce przed patrzeniem" ${ }^{\prime \prime}$. Przeciwnie, z patrzenia uczyniono tutaj imperatyw. Bez śledzących konta na Facebooku czy Instagramie nie miałyby najmniejszego sensu. Jesteśmy do patrzenia i podglądania zachęcani, a nawet niejako przymuszani. I to nie tylko jako "zaproszeni" do oglądania i podglądania. Także w aspekcie aktywności programowych algorytmów, instrumentów filtrowania i doboru treści pod kątem tego, co potencjalnie może nas zainteresować w ramach naszej sieciowej aktywności i preferencji. Widzialność strukturyzuje wszystko, o czym była dotąd mowa. Jej przeciwieństwo - niewidzialność - skazuje na nieobecność, niewiedzę, spycha w nieistnienie. Generuje nieustanny strach (który Leszek Koczanowicz nazywa "lękiem intymności"), że "coś nie zostanie pokazane, wypowiedziane, przedstawione", a "zatrzymane tylko dla siebie nie jest w pełni wartościowe, że jeżeli czegoś wszystkim nie ujawnimy, to stracimy szansę na pełne zaistnienie w świecie" ${ }^{1}$.

Podsumujmy całość następującymi wnioskami. Po pierwsze, przedstawione argumenty skłaniają ku założeniu, że doświadczenie prawdy i prawdziwości fotografii konstytuuje się w interpretacji i przez interpretacje, a ściślej kolejne kontekstualne reinterpretacje. Podstawą prawdziwości zdaje się wiarygodność zdjęcia kształtowana w odniesieniu nie do rzeczywistości, ale - jak ustaliliśmy - naszego postrzegania rzeczywistości, a ściślej kulturowych konstruktów

48. Fish, Interpretacja, retoryka, polityka..., 102.

49. Welsch, Na drodze do kultury styszenia..., 61.

50. Markowski, Dzień na Ziemi..., e-book.

51. Leszek Koczanowicz, "Lęk intymności, czyli mówienie prawdy w dobie internetu”, Kultura Współczesna nr 2/101, 2018, 43. 
rzeczywistości oraz współzależna z tym koherencja "relacji postrzegawczych" wobec fotografii i fotografowanego. Jednak nie tyle owe konstrukty wydają się tutaj kompleksem rozstrzygającym, ile presja i racje - jak podpowiadają Stanley Fish i rzecznicy kulturalizmu - kulturowych wspólnot interpretacyjnych (także Instagrama czy Facebooka), z perspektywy których jako interpretujące jaźnie historyczne ${ }^{52}$ konkretyzujemy zarówno wspomniane konstrukty rzeczywistości, jak i to, co w określonych okolicznościach i doraźnych systemach dyskursywnych za prawdę i prawdziwe uznajemy. Prawda i prawdziwość są zatem nieuchronnie zależne od kontekstu i dyskursywnie warunkowane. Przy tym podmioty interpretujące działają zgodnie z aktualnymi racjami i przesądzeniami wspólnot interpretacyjnych, które podzielają i uznają za swoje. W ten sposób nie są one nigdy przekonaniami jednostki "w jakimkolwiek sensie, który uzasadniałby obawę przed solipsyzmem. Oznacza to, że to nie ona jest ich źródłem [...]; to raczej ich wcześniejsza dostępność z góry wyznacza ścieżki, jakimi świadomość może pójśśc ${ }^{\prime 23}$. Po drugie, ciągłość interpretacji, już nie jako epistemologicznej a ontologicznej własności wyrażającej naszą aktywność bycia w świecie, prowadzi do identyczności oraz współzależności interpretacji i percepcji. Jak podkreślał Martin Heidegger "każde zwykłe, [...] dostrzeżenie czegoś [...] jest, samo w sobie, już rozumieniem i interpretacją" ${ }^{54}$. Po trzecie, jako "byty rozumujące" i reinterpretujące świat nie mamy dostępu do samej w sobie, czystej rzeczywistości. Nie odnosimy się do świata jako takiego, raczej do sposobu, w jaki świat istnieje dla nas, zawsze w perspektywie współokreślających go przesłanek i preferencji, uwarunkowań kulturowych, społecznych, dyskursywnych. Po czwarte, zważywszy, że nic nie jawi nam się niezinterpretowane i poza interpretacją (a nieustannie przecież interpretujemy), żyjemy nie tyle w świecie, ile raczej w obrazach świata, w kulturowych projekcjach i reprezentacjach. Dziś zdajemy sobie doskonale sprawę z tego, że "przedstawienia, nie wyłączając światoobrazu, były z nami zawsze i nie można poza nie wyjść, a tym bardziej nie można przekroczyć światoobrazu, by zyskać bardziej autentyczną relację z Byciem, z Realnym czy ze Światem"55. W efekcie, po piąte, myślenie, że prawda/prawdziwość fotografii konstytuuje się w odniesieniu do świata zewnętrznego, trzeba poddać modyfikacji: chodzi nie o rzeczywistość, ile obraz/y - kulturowe konstrukty rzeczywistości. Kształtowane przez wiele

52. "Przez każdego interpretatora przemawia bowiem zespół uświadamianych bądź nieuświadamianych przekonań o charakterze aksjologicznym i światopoglądowym, które podziela on z jakąś wspólnotą interpretacyjną, do której należy”. Andrzej Szahaj, "Sławiński o interpretacji. Analiza krytyczna", Teksty Drugie nr 5/2013, 264.

53. Fish, Interpretacja, retoryka, polityka..., 78.

54. Cyt. za: Katarzyna Rosner, Hermeneutyka jako krytyka kultury. Heidegger - Gadamer Ricoeur (Warszawa: Wydawnictwo PIW, 1991), 37.

55. Mitchell, Czego chca obrazy..., 28. 
zmiennych, $w$ tym także z uwzględnieniem relacji postrzegawczych odpowiadających - kulturowo skonwencjonalizowanej - konwergencji fotografii (obrazu) i rzeczywistości. Wszak jak zauważa Umberto Eco, wszelkie znaki ikoniczne, w tym fotografie/zdjęcia, wyzwalają

pewien model relacji między zjawiskami graficznymi, odpowiadający modelowi relacji postrzegawczych, jaki budujemy poznając dany przedmiot (desygnat), a model ten jest konstruowany i rozpoznawalny za pomocą tych samych zabiegów myślowych, jakich dokonujemy dla skonstruowania danego pojęcia - niezależnie od substancji, w której urzeczywistniają się odnośne relacje ${ }^{56}$.

Stąd problem nie tkwi tylko w stopniu czy wierności imitatywnego odwzorowania rzeczywistości przez zdjęcie (co we współczesnej wizualnej, okulocentrycznie zorientowanej kulturze ma niebagatelne znaczenie), ile raczej w naszych postrzeżeniowych doświadczeniach. A ściślej w koherencji naszych reakcji wobec zdjęcia i fotografowanej rzeczywistości, bądź prościej: obrazu i przedmiotu. W przeciwnym razie nie tylko nie moglibyśmy pojmować znaczeń (sensów) wysoce skonwencjonalizowanych znaków wizualnie niepodobnych i niemających wiele wspólnego z denotowanym zjawiskiem, ale także - dla części odbiorców pozbawionych kulturowo determinowanej zdolności do "przechodzenia od przedmiotu przedstawiającego do przedmiotu przedstawionego" ${ }^{57}$ - najbardziej wierne rzeczywistości fotografie będą tylko płaszczyzną punktów, linii, plam. Rejestracyjny fotorealizm zdjęcia nie znaczy nic dla odbiorcy pozbawionego "zdolności odtwórczej”, zdolności sensotwórczego porządkowania fotografii. Bez tego bezprzedmiotowe staje się wszystko, co dotąd powiedzieliśmy. Jak bowiem dywagować o istnieniu i prawdziwości czegoś, czego istnienia nie uwiarygodni percepcja odbiorcy. "Ślepiec Ruskina, jeśli nagle przejrzy, nie zobaczy świata na kształt obrazów Turnera czy Moneta - już Berkeley wiedział, że dozna jedynie bolesnego wrażenia chaosu, który będzie musiał uładzić drogą długiego terminowania" ${ }^{\text {. }}$. Zatem, po szóste, wszelkie uwiarygodniające prawdziwość fotografii własności i kryteria, łączone zwykle z jej techniczną specyfiką i rejestracyjnymi zdolnościami, okazują się także (a raczej przede wszystkim) pochodnymi naszych interpretacyjnych klasyfikacji. Skonwencjonalizowanymi kulturowo do tego

56. Eco, Nieobecna struktura..., 136.

57. Andrzej Lipski, "Sztuka a rzeczywistość potocznego doświadczenia. Świat artystyczny jako przedmiot analizy socjologicznej”, w: Andrzej Lipski i Krzysztof Łęcki, Perspektywy socjologii kultury artystycznej (Warszawa: Wydawnictwo PWN, 1992), 58.

58. Władysław Witwicki, Psychologia, t. 1 (Warszawa: Wydawnictwo PWN, 1962), 225. Cyt. za: Andrzej Lipski, "Sztuka a rzeczywistość potocznego doświadczenia. Świat artystyczny jako przedmiot analizy socjologicznej”, w: Andrzej Lipski i Krzysztof Łęcki, Perspektywy socjologii kultury artystycznej (Warszawa: Wydawnictwo PWN, 1992), 58. 
stopnia, że pretendujący do obiektywnego przedstawienia rzeczywistości konkret fotografii, związany z realizmem "prawdziwego odwzorowania", okazuje się także "uwarunkowany systemem reprezentacji preferowanym w danej społeczności" a szerzej - wspólnocie interpretacyjnej (bądź formacji dyskursywnej). Stąd też względny, konwencjonalny status realizmu/zgodności z realnym oraz "prawdziwego odwzorowania” ujawnia istotną wieloznaczność tych założeń, wyzwalającą nad wyraz sporo nieporozumień w obrębie pojmowania - znów kulturowo determinowanej, a przez to konwencjonalnej - zasady analogii do pozaartystycznej rzeczywistości. Po siódme, tym sposobem myślenia kwestionujemy także samoreferencyjność fotografii. Chociaż burzy to potoczne mniemania i racje zdrowego rozsądku, nie fotografia a odbiorca (obligowany kwestiami, o których wcześniej była mowa) w procesach percepcji i interpretacji konkretyzuje jej doraźne znaczenia i sensy. Znaczenie podlega zatem relokacji z obiektu w przestrzeń spotkania i związanych z tym interakcji, uwzględniających także to, co sami w to doświadczenie wnosimy. To my, odbiorcy - podkreśla Belting - "ożywiamy obrazy", gdy "napotykamy je w ich medialnych ciałach" 60 . A czynimy tak, ponieważ, parafrazując Bal, zdjęcie (jak tekst i obraz) nigdy "nie mówi samo za siebie. Obudowujemy je, nadajemy mu ramy, zanim w ogóle pozwolimy mu przemówić"61. Po ósme wreszcie, i tym stwierdzeniem zamknijmy całość, to, co uznajemy za prawdziwe i wiążemy z prawdziwością fotografii jawi nam się takim zawsze w obrębie określonych strategii dyskursywno-interpretacyjnych oraz w świetle kulturowych, skonwencjonalizowanych przesłanek, które ugruntowują nasze przeświadczenie, że tak właśnie jest. Ale także dlatego, że przeświadczenia te są “czynione takimi przez skuteczne akty interpretacji” 62.

59. Korusiewicz, Jak funkcjonuje..., 143.

60. Belting, Antropologia obrazu..., 15.

61. Bal, Wędrujące pojęcia..., 31. “To, co widzialne - obraz i jego znaczenie - rozumiane są nie jako rzecz na zawsze ustalona, lecz uzależniona od rzutowanych na nią stanowisk i schematów interpretacyjnych". Stuart Hall, "Introduction: Looking and Subjectivity”, w: Visual Culture: The Reader, red. Jessica Evans, Stuart Hall (London: Sage, 1999), cyt. za: Gillian Rose, Krytyczna metodologia badań..., 140.

62. Fish, Interpretacja, retoryka, polityka..., 150. 


\section{Bibliografia}

Bal, Mieke. Wędrujące pojęcia w naukach humanistycznych. Krótki przewodnik, przeł. Maria Bucholc. Warszawa: NCK, 2012.

Barthes, Roland. Światło obrazu. Uwagi o fotografii, przeł. Jacek Trznadel. Warszawa: Aletheia, 1996.

Baudrillard, Jean. "Precesja symulakrów”, przeł. Tadeusz Komendant. W: Postmodernizm. Antologia przekładów, 175-189. Kraków: Wydawnictwo Baran i Suszczyński, 1998.

Bazin, André. "Ontologia obrazu fotograficznego", przeł. Bolesław Michałek. W: Fotospołeczeństwo. Antologia tekstów z socjologii wizualnej, red. Małgorzata Bogunia-Borowska i Piotr Sztompka, 121-426. Kraków: Znak, 2012.

Belting, Hans. Antropologia obrazu. Szkice do nauki o obrazie, przeł. Mariusz Bryl. Kraków: Universitas, 2007.

Benjamin, Walter. Anioł historii. Eseje, szkice, fragmenty, przeł. Krystyna Krzemieniowa i inni. Poznań: Wydawnictwo Poznańskie, 1996.

Boehm, Gottfried. O obrazach i widzeniu. antologia tekstów, red. Daria Kołacka, przeł. Małgorzata Łukasiewicz, Anna Pieczyńska-Sulik. Kraków: Universitas, 2014.

Drozdowski, Rafał. “Obrazów nigdy dosyć - pod warunkiem, że nie służą jedynie do oglądania”. Kultura Współczesna 1/76, 2013.

Dziamski, Grzegorz. Kulturoznawstwo, czyli wprowadzenie do kultury ponowoczesnej. Gdańsk: Wydawnictwo Naukowe Katedra, 2016.

Eco, Umberto. Nieobecna struktura, przeł. Adam Weinsberg, Paweł Bravo. Warszawa: Wydawnictwo KR, 1996.

Eco, Umberto. Semiologia życia codziennego, przeł. Piotr Salwa, Joanna Ugniewska. Warszawa: Czytelnik, 1998.

Fish, Stanley. Interpretacja, retoryka, polityka. Eseje wybrane, red. Andrzej Szahaj, przeł. Krzysztof Abriszewski i inni. Kraków: Universitas, 2008.

Foucault, Michel. Archeologia wiedzy, przeł. Andrzej Siemek. Warszawa: PIW, 1977.

Foucault, Michel. Historia seksualności, przeł. Bogdan Banasiak, Tadeusz Komendant, Krzysztof Matuszewski. Warszawa: Czytelnik, 2000.

Foucault, Michel. Historia szaleństwa $w$ dobie klasycyzmu, przeł. Helena Kęszycka. Warszawa: PIW, 1987.

Gadamer, Hans-Georg. Prawda i metoda. Zarys hermeneutyki filozoficznej, przeł. Bogdan Baran. Kraków: Inter esse, 1993.

Hall, Stuart. "Introduction: Looking and Subjectivity". W: Visual Culture: The Reader, red. Jessica Evans, Stuart Hall. London: Sage, 1999.

Kalaga, Wojciech. Mgławice dyskursu. Podmiot, tekst, interpretacja. Kraków: Universitas, 2001.

Koczanowicz, Leszek. "Lęk intymności, czyli mówienie prawdy w dobie internetu”. Kultura Współczesna nr 2/101, 2018, 38-50.

Korusiewicz, Maria. "Jak funkcjonuje dzieło sztuki, czyli muzeum według Nelsona Googmanna”. W: Muzeum sztuki. Antologia, 135-145. Kraków: Universitas, 2005. 
Kuhn, Thomas. Struktura rewolucji naukowych, przeł. Helena Ostromęcka. Warszawa: PWN, 1968.

Lipski, Andrzej. “Sztuka a rzeczywistość potocznego doświadczenia. Świat artystyczny jako przedmiot analizy socjologicznej”. W: Perspektywy socjologii kultury artystycznej, 8-143. Warszawa: Wydawnictwo PWN, 1992.

Margolis, Joseph. Czym, w gruncie rzeczy, jest dzieło sztuki? Wykłady z filozofii sztuki, przeł. Wojciech Chojna i inni. Kraków: Universitas, 2004.

Markowski, Michał Paweł. Dzień na Ziemi. Proza podróżna. Poznań: Wydawnictwo Poznańskie, 2014.

Mitchell, William John Thomas. Czego chca obrazy? Pragnienia przedstawień, życie i miłości obrazów, przeł. Łukasz Zaremba. Warszawa: NCK, 2013.

Mirzoeff, Nicholas. "What is Visual Culture?". W: The Visual Culture Reader, red. Nicolas Mirzoeff. London-New York: Routledge, 1998.

Olechnicki, Krzysztof. “Łap chwilę... powoli”. Kultura Współczesna nr 1/76, 2013.

Pruś, Jakub. “Teorie prawdy: klasyczna, korespondencyjna i semantyczna — próba uściślenia relacji”. Rocznik Filozoficzny Ignatianum XXIV/2, 2018, 57-83: https://czasopisma. ignatianum.edu.pl/index.php/rfi.

Rorty, Richard. Obiektywność, relatywizm i prawda, przeł. Janusz Margański. Warszawa: Aletheia, 1999.

Rose, Gillian. Krytyczna metodologia badań nad wizualnościa, przeł. Ewa Klekot. Warszawa: PWN, 2015.

Rosner, Katarzyna. Hermeneutyka jako krytyka kultury. Heidegger - Gadamer - Ricoeur. Warszawa: PIW, 1991.

Rosner, Katarzyna. Narracja, tożsamość i czas. Kraków: Wydawnictwo Universitas, 2003.

Sontag, Susan. Ofotografii, przeł. Sławomir Magala. Warszawa: Wydawnictwo Artystyczne i Filmowe, 1986.

Sułkowska, Mariola. Ciało w fotografii”. Kultura Współczesna nr 1-2/23-24, 2000, 105-109: https://www.nck.pl/upload/archiwum_kw_files/artykuly/15._mariola_sulkowska_-_cialo_w_fotografii.pdf.

Szahaj, Andrzej. “Zniewalająca moc kultury” [Przedmowa]. W: Interpretacja, retoryka, polityka. Eseje wybrane, red. Andrzej Szahaj, przeł. Krzysztof Abriszewski i inni, 13-28. Kraków: Universitas, 2008.

Szahaj, Andrzej. “Sławiński o interpretacji. Analiza krytyczna”. Teksty Drugie nr 5/2013, 259-275.

Virilio, Paul. “Maszyna widzenia”, przeł. Barbara Kita. W: Widzieć, myśleć, być. Technologie mediów, red. Andrzej Gwóźdź, 39-62. Kraków: Universitas, 2001.

Welsch, Wofgang. "Na drodze do kultury słyszenia?”, przeł. Krystyna Wilkoszewska. W: Przemoc ikoniczna czy "nowa widzialność", red. Eugeniusz Wilk, 56-74. Katowice: Wydawnictwo Uniwersytetu Śląskiego, 2001.

Witwicki, Władysław. Psychologia, t. 1. Warszawa: Wydawnictwo PWN, 1962.

Woleński, Jan. Metamatematyka a epistemologia. Warszawa: PWN, 1993. 